\title{
A PREVIDÊNCIA SOCIAL COMO POLÍTICA DE DISTRIBUIÇÃO E REDISTRIBUIÇÃO DE RENDA
}

\author{
Juliana Toralles dos Santos Braga ${ }^{1}$ \\ Ana Maria Correa Isquierdo ${ }^{2}$
}

\section{RESUMO}

A desigualdade social e a redistribuição de renda estão no centro dos conflitos políticos do Brasil. Dessa forma, a indagação que move este trabalho é: a Previdência Social apresenta-se como uma política de distribuição e redistribuição de renda no país? Primeiramente, discutese como o neoliberalismo agravou a desigualdade social e prejudicou o processo de redistribuição de renda. Após, se mostrará como esse processo político-econômico afetou a Previdência Social brasileira, bem como quais foram as consequências suportadas pelos segurados do RGPS. Para tanto, será utilizado o método indutivo, bem como será abordada pesquisa bibliográfica e documental.

Palavras-chave: Desigualdade social; redistribuição de renda; Previdência Social; neoliberalismo.

\section{SOCIAL SECURITY AS A POLICY OF DISTRIBUTION AND REDISTRIBUTION}

\begin{abstract}
Social inequality and redistribution of income are at the center of Brazil's political conflicts. Thus, the question that moves this work is: Does Social Security present itself as a policy of distribution and redistribution of income in the country? First, it is discussed how neoliberalism aggravated social inequality and undermined the process of income redistribution. Afterwards, it will be shown how this political-economic process affected Brazilian Social Security, as well as what were the consequences borne by RGPS policyholders. For this purpose, the inductive method will be used, as well as bibliographical and documentary research.
\end{abstract}

Keywords: Social inequality; income redistribution; Social Security; neoliberalism.

\section{INTRODUÇÃOO}

Os sistemas de Previdência Social passaram a ganhar evidência após a Crise de 1929, diante do desamparo social da grande massa de trabalhadores. A desigualdade social e a redistribuição de renda, por sua vez, têm estado no centro dos conflitos políticos, nos quais há divergência entre os mecanismos sociais e econômicos que geram a desigualdade e, consequentemente, do que deve nortear a ação pública de redistribuição.

\footnotetext{
${ }^{1}$ Mestre em Direito e Justiça Social pela Faculdade de Direito da Universidade Federal do Rio Grande - FURG. Pesquisadora do Projeto de Pesquisa Cidadania, Direitos e Justiça - CIDIJUS. Especialista em Direito Previdenciário pela Universidade Anhanguera - Uniderp. Especialista em Direito Público pela Universidade Anhanguera - Uniderp. Advogada.

${ }^{2}$ Mestre em Direito e Justiça Social pela Faculdade de Direito da Universidade Federal do Rio Grande - FURG. Especialização em Direito de Familia e Sucessões (ULBRA) e Direito do Trabalho e Previdenciário (FACULDADES ATLÂNTICO SUL/PELOTAS). Advogada.
} 
Nesse sentido, as políticas públicas de Previdência Social têm papel extremamente importante, especialmente levando-se em conta o efeito distributivo dos benefícios previdenciários, isto é, o impacto que o gasto previdenciário gera sobre a desigualdade de renda. O Regime Geral de Previdência Social do Brasil se pauta tanto na reposição de renda em caso de perda de capacidade laborativa quanto na redução da pobreza por meio da distribuição de recursos de grupos mais afluentes para os menos, contudo vem sofrendo constantes reformas guiadas pelo ideário neoliberal.

Daí a importância do presente artigo, o qual se identifica com o objetivo do XXVII Encontro Nacional do Conpedi, cujo tema é "Direito, Cidade Sustentável e Diversidade Cultural", com o propósito de oferecer elementos para uma reflexão que subsidie o debate em torno das políticas sociais no Brasil e do papel da Previdência Social na redução de desigualdade social e na redistribuição de renda. Conquanto, vale destacar que sustentabilidade também consiste em delinear ações humanas que visem suprir as necessidades atuais dos seres humanos, sem afetar o futuro das próximas gerações.

A indagação central deste trabalho, a ser confirmada ou não durante a pesquisa ora empreendida, pode assim ser resumida: a Previdência Social apresenta-se como uma política de distribuição e redistribuição de renda em nosso País?

Para tanto, será utilizado o método indutivo, bem como será abordada pesquisa bibliográfica e documental. Os instrumentos e fontes escolhidos para a coleta de dados foram legislação, doutrina, periódicos e sítios da Internet. Para a pesquisa bibliográfica, a proposta de seleção das leituras foi seletiva, crítica ou reflexiva e analítica.

Sendo assim, na primeira parte do trabalho propomo-nos a traçar um breve panorama sobre como o neoliberalismo agravou a desigualdade social e prejudicou o processo de redistribuição de renda, com base na doutrina do economista Thomas Piketty, do sociólogo Zygmunt Bauman, do geógrafo David Harvey e do jurista Enzo Bello, entre outros.

Por fim, será realizado o exame de um processo de neoliberalização que atingiu seu auge na América Latina na década de 90 e afetou a Previdência Social brasileira, bem como quais foram as consequências suportadas pelos segurados do RGPS.

\section{DESIGUALDADE SOCIAL, REDISTRIBUIÇÃO DE RENDA E NEOLIBERALISMO}

É indiscutível que a desigualdade social e a redistribuição de renda estão no centro dos conflitos políticos. Thomas Piketty, economista reconhecido por suas obras sobre 
distribuição de renda ${ }^{3}$, coloca que é possível afirmar que o conflito político central reside entre a posição liberal de direita e a posição tradicional de esquerda.

Para a posição liberal de direita só as forças do mercado, a iniciativa individual e o aumento da produtividade promovem em longo prazo uma melhora efetiva da renda e das condições de vida, em particular dos mais desfavorecidos, de forma que a ação pública de redistribuição deve ser moderada, "se limitando a instrumentos que interfiram o mínimo possível nesse mecanismo virtuoso - como, por exemplo, o sistema integrado de tributação e transferências (imposto negativo) de Milton Friedman [1962]” (PIKETTY, 2015, p. 9). Já para a posição tradicional de esquerda, com origem nos teóricos socialistas do século XIX e na prática sindical, a ação pública de redistribuição deve ser bem mais ampla, transpondo o núcleo do processo de produção, contestando as forças do mercado e a desigualdade entre os assalariados, uma vez que "afirma que somente as lutas sociais e políticas são capazes de atenuar a miséria dos menos favorecidos produzida pelo sistema capitalista" (PIKETTY, 2015, p. 9).

Esse conflito direita/esquerda mostra, em primeiro lugar, que as discordâncias quanto à forma concreta e à adequação de uma ação pública de redistribuição não se devem necessariamente a princípios antagônicos de justiça social, mas sobretudo a análises antagônicas dos mecanismos econômicos e sociais que produzem a desigualdade. Com efeito, há certo consenso a respeito de diversos princípios básicos de justiça social (PIKETTY, 2015, p. 10)

Com relação aos sistemas de previdência social cumpre lembrar que eles ganharam evidência justamente após a Crise de 1929, diante do desamparo social da grande massa de trabalhadores.

Pouco tempo antes, em 1926, John Keynes já havia elaborado o clássico no panfleto "O fim do "laissez-faire", sinalizando uma crise do liberalismo clássico:

Atualmente não existe um partido no mundo que me pareça estar querendo atingir os objetivos certos, pelos métodos certos. A pobreza material fornece estímulos à mudança precisamente em situações em que existe muito pouca margem para experiências. A prosperidade material remove tais estímulos justamente quando seria seguro tentar realizá-los. A Europa carece dos meios, e a América da vontade de fazer um movimento. Precisamos de um novo conjunto de convicções que saltem naturalmente de um exame ingênuo de nossos sentimentos interiores em relação aos fatos exteriores. (KEYNES, 1983. p.9)

Potyara destaca que a crise do sistema econômico liberal produziu significativas mudanças na ideologia e na prática prevalecente do laissez-faire, abrindo espaços para uma

\footnotetext{
${ }^{3}$ Por sua obra, recebeu no ano 2013 o Prêmio Yrjö Jahnsson, conferido pela Associação Europeia de Economia.
} 
efetiva intervenção do Estado na economia e na sociedade. Já no plano econômico, o intervencionismo ganhava força através da ideia de segurança da existência, a qual postula a instauração e a organização de sistemas de seguridade pública como direito do cidadão e obrigação do Estado (POTYARA, 1997, p. 61).

Nessa esteira, o capitalismo passou a ceder espaço às chamadas políticas keynesianas, em um momento histórico no qual os movimentos de esquerda (socialismo/comunismo) e de direita (fascismo/nazismo) possuíam bastante força - conflito supracitado apontado por Piketty (2015). E, nesse sentido, os direitos sociais foram legalmente reconhecidos e as políticas sociais se expandiram no limite entre a conquista de direitos e a reestruturação do capital, o que significa reconhecer que "os direitos sociais são capitalistas e sua ampliação não assegura a emancipação humana, mas podem contribuir para criar as condições materiais para melhoria das condições de vida" (BOSCHETTI, 2010, p. $68)$.

Durante o Welfare State o Estado intervencionista promoveu uma economia social e moral, se transformando em um campo de força que internalizou relações de classe, ao passo que sindicatos e partidos políticos de esquerda tiveram uma influência bastante concreta em seu aparato.

No entanto, o desemprego e a inflação não paravam de crescer, o que provocou uma fase global de estagflação que duraria até parte dos anos 1970, com a crise da acumulação do capital.

Esse panorama apontou para "a emergência de uma alternativa socialista ao compromisso social entre capital e trabalho que fundamentara com tanto sucesso a acumulação do capital no pós-guerra" e, na ocasião, as forças populares e os partidos comunistas e socialistas se expandiam na Europa e até mesmo nos Estados Unidos, o que representava uma verdadeira ameaça política às elites econômicas e às classes dirigentes em toda parte, tanto em países capitalistas avançados como em muitos países em desenvolvimento (HARVEY, 2008, p. 20-23).

Na obra "A mundialização do capital”, o economista Françóis Chesnais realiza uma análise da economia política do capitalismo e descreve a "mundialização do capital" como uma fase que se iniciou no decorrer da década de 1980, na qual "o capitalismo parece ter triunfado e parece dominar todo o planeta, mas os dirigentes políticos, industriais e financeiros dos países do G7 cuidam de se apresentarem como portadores de uma missão histórica de progresso social" (CHESNAIS, 1996, p. 14). Quanto ao capitalismo do século $\mathrm{XX}$ sinala que 
a acumulação de capital se dá pelas novas formas de centralização de gigantescos capitais financeiros (os fundos mútuos e fundos de pensão), cuja função é frutificar principalmente no interior da esfera financeira. Seu veículo são os títulos (securities) e sua obsessão, a rentabilidade aliada à "liquidez", da qual Keynes denunciara o caráter "anti-social", isto é, antiético ao investimento de longo prazo. Não é mais um Henry Ford ou um Carnegie, e sim o administrador praticamente anônimo (e que faz questão de permanecer anônimo) de um fundo de pensão com ativos financeiros de várias dezenas de bilhões de dólares, quem personifica o "novo capitalismo" de fins do século XX (CHESNAIS, 1996, p. 14).

O processo de mundialização do capitalismo se deu simultaneamente ao advento do neoliberalismo e afetou diretamente as políticas públicas de previdência social, as quais estão atreladas a um contexto histórico e social.

FERRARO releva que é sintomático o fato de o neoliberalismo ter surgido precisamente no momento em que o liberalismo clássico "especialmente em sua versão laissez-fairista, já era dado por morto e sepultado", uma vez que "o fim do laissez-faire, de Keynes, de 1926, há apenas três anos da Grande Crise, repercutira como atestado de óbito do liberalismo" (2004, p. 101).

Boaventura de Sousa Santos discorre sobre o consenso neoliberal na globalização:

A globalização, longe de ser consensual, é, como veremos, um vasto e intenso campo de conflitos entre grupos sociais, Estados e interesses hegemónicos, por um lado, e grupos sociais, Estados e interesses subalternos, por outro; e mesmo no interior do campo hegemónico há divisões mais ou menos significativas. No entanto, por sobre todas as suas divisões internas, o campo hegemónico actua na base de um consenso entre os mais influentes membros. É esse consenso que não só confere à globalização as suas características dominantes, como também legitima estas últimas como as únicas possíveis ou as únicas adequadas. (...) Este consenso é conhecido por "consenso neoliberal" ou "Consenso de Washington" por ter sido em Washington, em meado da década de oitenta, que ele foi subscrito pelo Estados Centrais do sistema mundial, abrangendo o futuro da economia mundial, as políticas de desenvolvimento e especificamente o papel do Estado na economia (SANTOS in SANTOS, 2002, p. 27).

Assim proposta a doutrina neoliberal ${ }^{4}$ na primeira metade do século $\mathrm{XX}$, voltada para a adaptação dos princípios do liberalismo clássico às exigências de um Estado regulador e assistencialista.

\footnotetext{
${ }^{4}$ Não há consenso quanto à gênese do movimento. Para alguns autores, como Ferraro (2004), o neoliberalismo se constituiu como movimento organizado no Colóquio Walter Lippmann, em Paris, em agosto de 1938, e ascendeu à condição de pensamento único e dominante a partir da crise do Welfare State na década de 1970. Outros, como Anderson (1995), entendem que o movimento nasceu em 1947, em uma reunião para a qual Hayek convocou aqueles que compartilhavam sua orientação ideológica - entre eles Milton Friedman, Ludwig Von Mises, Lionel Robbins, Walter Eupken, Walter Lipman, Michael Polanyi, Salvador de Madariaga - , ocorrida na pequena estação de Mont Pèlerin, na Suíça.
} 
O neoliberalismo, é em primeiro lugar, uma teoria das práticas político-econômicas que propõe que o bem-estar humano pode ser melhor promovido liberando-se as liberdades e capacidades empreendedoras individuais no âmbito de uma estrutura institucional caracterizada por sólidos direitos à propriedade privada, livres mercados e livre comércio. $\mathrm{O}$ papel do Estado é criar e preservar uma estrutura institucional apropriada a essas práticas; o Estado tem de garantir, por exemplo, a qualidade e a integridade do dinheiro (HARVEY, 2008, p. 11).

Este movimento, que passou a ser hegemônico a partir de 1970 (HOBSBAWM, 1995), chegando vinte anos mais tarde nos países denominados "terceiro mundistas", ou "em desenvolvimento", preconizou, como maior bandeira, o encolhimento do Estado no que respeita à sua participação nas políticas sociais. Ele representa, em resumo rápido, "uma reação contra as novas concepções e propostas que abriram caminho para o planejamento econômico, o Keynesianismo e as políticas de bem-estar social, e, por outro lado, a afirmação explícita do retorno às idéias e ideias que nortearam a grande expansão industrial do século XIX. (FERRARO, 1997)

A teoria neoliberal obteve respeitabilidade acadêmica, a qual aliada a todo o apoio político recebido na época, atribuiu caráter hegemônico a ela. Em 1974, Friedrich August von Hayek - um dos principais expoentes do neoliberalismo - recebeu o Prêmio de Ciências Econômicas em Memória de Alfred Nobel, sob o fundamento de que sua pesquisa teria ultrapassado a pura ciência econômica, com trabalhos significativos no campo da pura teoria econômica, os quais teriam ampliado horizontes "para incluir amplos aspectos nos fenômenos sociais e institucionais" (THE PRIZE IN ECONOMICS, 1974). Dois anos após, em 1976, o mesmo prêmio foi concedido a Milton Friedman - outro grande nome do neoliberalismo -, "por suas realizações nos campos de análise de consumo, história monetária e teoria e por sua demonstração da complexidade da política de estabilização" (THE SVERIGES RIKSBANK PRIZE IN ECONOMIC SCIENCES IN MEMORY OF ALFRED NOBEL, 1976).

David Harvey, na obra "O Neoliberalismo: História e Implicações”, constata que a tradição imperial norte-americana vinha se forjando e em larga medida se definia contra as tradições imperiais da Grã-bretanha, da França, da Holanda e de outras potências européias. Enquanto no final do século XIX acalentaram a idéia de conquista colonial, no século XX os Estados Unidos desenvolveram "um sistema mais aberto de colonialismo sem colônias" (HARVEY, 2008, p. 35). E completa

Ávidos por crédito, os países em desenvolvimento foram estimulados a se endividar pesadamente, com taxas vantajosas para os banqueiros de Nova York. Mas, como os empréstimos eram em dólares norte-americanos, todo aumento modesto, para não falar dos acentuados, nas taxas de juro nos 
Estados Unidos podia facilmente levar países vulneráveis à inadimplência, expondo os bancos de investimento de Nova York a sérias perdas.

[...]O FMI e o Banco Mundial se tornaram a partir de então centros de propagação e implantação do fundamentalismo do livre mercado e da ortodoxia neoliberal. Em troca de reescalonamento da dívida, os países endividados tiveram de implementar reformas institucionais como cortes nos gastos sociais, leis do mercado de trabalho mais flexíveis e privatização. (HARVEY, 2008, pp. 36-37)

Santos sustenta que a globalização econômica é amparada pelo "consenso econômico neoliberal", o qual apresenta como uma das principais inovações institucionais a subordinação dos Estados nacionais às agências multilaterais tais como Banco Mundial e o FMI. Destaca também que são os países periféricos e semiperiféricos os que mais estão sujeitos às imposições do receituário neoliberal, uma vez que esse é transformado pelas agências financeiras multilaterais em condições de renegociação da dívida externa através dos programas de ajustamento estrutural (SANTOS in SANTOS, p. 31).

No que tange ao Brasil e aos países latino-americanos, dependentes financeiramente, o auge do modelo neoliberal, com reflexos significativos nos direitos sociais previdenciários, foi a década de 90 .

A partir de 1970 se expandiu na América Latina o que se convencionou chamar de padrão neoliberal de desenvolvimento. Ele se iniciou com experiências localizadas no Chile, Argentina e Uruguai, ganhou impulso nos anos 1980 e atingiu o seu auge nos 1990, tornando-se predominante na região com o estabelecimento do Consenso de Washington (MARTINS, 2011, p. 313).

Enfim, a neoliberalização significou a "financeirização", o que aprofundou o domínio das finanças sobre todas as outras áreas da economia, assim, como sobre o aparato do Estado, e, "Mais do que nunca o poder se concentra em pequenos grupos econômicos, e os países do capitalismo central seguem ditando regras que devem ser cumpridas pelos países de capitalismo periféricos" (BOSCHETTI, 2010, p. 67).

Nos Estados Unidos, o controle da riqueza (em oposição à renda) pelo $1 \%$ mais rico da população permaneceu mais ou menos estável por todo o século XX. Mas na década de 1970 sofreu acentuada queda com o colapso do valor dos ativos (ações, imóveis, poupanças). As classes altas tinham de agir com mais vigor para se proteger da aniquilação política e econômica.

(...) Efeitos redistributivos e uma desigualdade social crescente têm sido de fato uma característica tão persistente do neoliberalismo que podem ser considerados estruturais em relação ao projeto como um todo. Gérard Duménil e Dominique Lévy, depois de uma cuidadosa redistribuição dos dados, concluíram que a neoliberalização foi desde o começo um projeto voltado para restaurar o poder de classe. (HARVEY, 2008, p. 24-25)

Chesnais destaca, com relação ao sentido e ao conteúdo de acumulação de capital e dos seus resultados na fase que chama de "mundialização do capital", na qual ingressamos no 
decorrer da década de 1980, que os administradores dos fundos de pensão personificaram o "novo capitalismo" de fins do século XX (CHESNAIS, 1996, p. 14).

Os neoliberais não poupavam críticas à previdência pública. Friedman, por exemplo, acastela que o público não funciona, ao contrário do sistema privado - o qual entende eficaz e seguro. O economista defende que "cada pessoa poderia ser solicitada a pagar sua própria anuidade; deveria ser permitido aos indivíduos comprar uma anuidade de firmas privadas”, e, assim, obriga-la "a comprar uma anuidade fica justificado não pelo seu próprio bem, mas pelo bem de todos" (FRIEDMAN, 1988, p. 95).

A crença de que grande fração da comunidade se tornaria um peso social se não fosse obrigada a comprar as anuidades deve sua viabilidade, na época em que o programa foi estabelecido, à Grande Depressão. Anualmente, de 1931 a 1940, mais de um sétimo da força de trabalho estava desempregada. E o desemprego era proporcionalmente maior entre os mais velhos. Mas tratou-se de experiência sem precedentes e que não se repetiu desde então. $\mathrm{O}$ problema não surgiu porque as pessoas eram imprevidentes e não foram capazes de garantir a própria velhice. Tratou-se de uma consequência, como já vimos, da incapacidade do governo. O programa é uma cura, se é que pode ser assim considerado, para uma moléstia muito diferente - e da qual não tínhamos tido nenhuma experiência. (FRIEDMAN, 1988, p. 98)

Piketty, por sua vez, pontua:

A imperfeição do mercado de crédito, ou mais simplesmente o fato de que "só se empresta aos ricos", está na origem da desigualdade ineficiente mais transparente possível, ainda que nem sempre saibamos identificar os instrumentos que permitem combatê-la de maneira eficaz. Na realidade, os problemas de motivação e informação que estão na origem do racionamento de crédito se aplicam da mesma maneira a todo mercado intertemporal, em especial ao mercado de seguros. Isso poderia explicar por que o mercado é incapaz de fornecer corretamente os seguros sociais fundamentais, justificando assim os sistemas públicos e obrigatórios de proteção social no âmago do intervencionismo moderno. (2015, p. 28)

E, dessa forma, a década de 1980 é reconhecida como a "década perdida" em termos econômicos para os países da América Latina em razão da conjugação de uma forte recessão com um exponencial aumento da dívida externa (BELLO, 2012, p. 56).

$\mathrm{Na}$ obra “A riqueza de poucos beneficia a todos nós?", o sociólogo Zygmunt Bauman traz dados empíricos sobre a desigualdade mundial, pontuando que:

O quadro geral deixa pouco ou nenhum espaço a dúvida: como hoje se apresenta, as coisas, o crescimento econômico (tal como descrito nas estatísticas do PIB e identificado com montantes crescentes de dinheiro mudando de mãos) não pressagia, para a maioria de nós, a chegada de um futuro melhor. Em vez disso, prognostica que um número já esmagador e rapidamente crescimento de pessoas se tornará ainda mais profundo e severamente desigual, com condições ainda mais precárias; e prevê, assim, também mais degradação, tristeza, afronta e humilhação - uma luta ainda mais dura pela sobrevivência social. (2015, p. 49) 
E continua concluindo que

O enriquecimento dos ricos não promove em "efeito de gotejamento" nem para aqueles situados em sua vizinhança mais próximas nas hierarquias de riqueza e renda - sem falar daqueles que estão mais distantes, escada abaixo. A conhecia, embora cada vez mais ilusória, "escada" de mobilidade ascendente está se transformando cada vez mais numa pilha de grades impermeáveis e barreiras intransponíveis. (2015, p. 49-50)

Os economistas Jonathan Ostry, Prakash Loungani e Davide Furceri publicaram um artigo na revista Finance \& Development, editada pelo próprio Fundo Monetário Internacional (FMI), em junho de 2016, supreendentemente questionando os exageros dos 30 anos neoliberais, reconhecendo que em vez de gerarem crescimento, algumas políticas neoliberais aumentaram a desigualdade e colocaram em risco uma expansão duradoura, concluindo que:

Essas descobertas sugerem a necessidade de uma visão mais matizada do que a agenda neoliberal provavelmente conseguirá. O FMI, que supervisiona o sistema monetário internacional, esteve na vanguarda desta reconsideração. (...) A experiência pioneira do Chile com o neoliberalismo recebeu o grande elogio do premiado com o Prêmio Nobel Friedman, mas muitos economistas agora se aproximaram da visão mais matizada expressada pelo professor da Universidade Columbia, Joseph Stiglitz (ele mesmo, Prêmio Nobel) de que o Chile "é um exemplo de sucesso de combinar mercados com regulação apropriada "(2002). Stiglitz observou que, nos primeiros anos de seu movimento para o neoliberalismo, o Chile impôs "controles sobre as entradas de capital, para que não fossem inundados", como, por exemplo, o primeiro país de crise asiática, a Tailândia, foi uma década e meio depois. A experiência do Chile (o país agora evita controles de capital), e a de outros países, sugere que nenhuma agenda fixa oferece bons resultados para todos os países para todos os tempos. Os formuladores de políticas e instituições como o FMI que os aconselham, devem ser guiados não pela fé, mas pela evidência do que funcionou. (OSTRY, LOUNGANI, FURCERI, 2016, p. 41, tradução da autora)

É possível avistar, assim, uma moderação do entusiasmo do neoliberalismo inicial das duas últimas décadas, através da aceitação da existência de uma variedade maior de caminhos para o bem-estar:

Os informes dos organismos internacionais já não apresentam a radicalização neoclássica dos anos 1980 e 1990. Reconhecem as imperfeições mercantis e destacam a primazia da ação estatal em certas áreas (meio ambiente, capital humano, infraestrutura). Essas mensagens combinam o discurso ortodoxo com a intervenção pública e propõem novos remédios para a estabilidade dos preços e os entraves na circulação da informação.

Este neoliberalismo mais atenuado também enfatiza a importância do assistencialismo. Aceita a despesa pública para conter a explosão da pobreza como um preço a pagar durante o processo de transição. Acredita que essa política de distribuição de renda será passageira e deverá se extinguir quando o modelo conseguir gerar mais emprego. Os fatos demonstram o enorme 
impacto das grandes sublevações que atemorizaram os capitalistas. (KATZ, 2016, p. 87)

Ainda assim, os ideais neoliberais continuam norteando os projetos que estão sendo postos em prática atualmente no Brasil, conforme será estudado a seguir, os quais demonstram que a decadência do neoliberalismo é um longo período:

\begin{abstract}
com marchas e contramarchas, tornando-se precipitado declarar o seu obituário, uma vez que, na América Latina, tal paradigma tem suas bases no México, na Colômbia, no Peru e no Chile, condicionado ainda à política macroeconômica de países como o Brasil, dirigido por uma esquerda de tipo terceira via. O neoliberalismo redimensionou as relações de dependências, desestruturou as políticas de substituição de importações e criou novas formas de vinculação da região à economia mundial. (MARTINS, 2011, p. 313)
\end{abstract}

Após a análise da influência neoliberal e suas consequências para os países latinoamericanos, não restam dúvidas no sentido de que esse modelo gerou um quadro maior de desigualdades e injustiças sociais.

\title{
2 A VISÃO NEOLIBERAL LANÇADA SOBRE A PREVIDÊNCIA SOCIAL DO BRASIL
}

O neoliberalismo tem influenciado reformas sucessivas na Previdência Social do Brasil desde a década de 90, tão logo após o processo de restituição do Estado democrático posterior a um longo período de ditadura militar - com ampliação dos direitos sociais na Constituição da República Federativa do Brasil de 1988.

José Ricardo Caetano Costa acrescenta que

Se é verdade que a Constituição Federal de 1988, fruto de uma efervescência político-cultural após os longos vinte anos de ditadura militar, caminhou na construção de um Estado Democrático de Direito, com indiscutível avanço no campo dos direitos sociais, também é verdade que, tão logo promulgada, houve um contra-movimento buscando o desfazimento destes direitos (COSTA in BRAUNER; LOBATO, 2015).

Cumpre, antes de mais, esclarecer que se optou pela limitação temática do presente estudo às modificações operadas no Regime Geral de Previdência Social (RGPS).

A primeira grande "Reforma da Previdência Social" no RGPS ocorreu através da promulgação da Emenda Constitucional $n^{\circ}$. 20, de 16 de dezembro de 1998. A proposta de emenda constitucional foi encaminhada em março de 1995 pelo então Presidente da República, Fernando Henrique Cardoso, ao Congresso Nacional, e, tramitou na forma da PEC $n^{\circ} 33 / 95$. Essa proposta de emenda gerou um grande debate, que levou à sua lenta tramitação. 
Os partidos da oposição da época rejeitaram insistentemente a PEC por entenderem que se tratava mais de uma tentativa de supressão de direitos, com vistas a contribuir para o ajuste das contas públicas e gerar condições para o desenvolvimento de um mercado privado de Previdência Social, que uma efetiva e verdadeira reforma da Previdência Social. Com razão, pois o próprio governo declarava a intenção de gerar condições para isso no Livro Branco:

A reforma manterá o Regime Geral de Previdência Social (RGPS) público e compulsório para todos os trabalhadores da iniciativa privada. Ao mesmo tempo, o governo estimulará a criação de regimes de aposentadorias complementares patrocinados pelas empresas os chamados fundos de pensão - que poderão ter contribuições do empregado e do empregador. Haverá também estímulos para que os trabalhadores que desejarem constituam programas de poupança para fins de complementação da renda na época da aposentadoria. (LIVRO BRANCO DA PREVIDÊNCIA SOCIAL, 1997, p. 45)

No mesmo documento critica as regras previstas na $\mathrm{CF} / 88$ e na legislação posterior, considerando que "incorporaram, de certa forma, os erros e os vícios anteriores. Em sua elaboração predominaram, mais uma vez, a falta de rigor técnico e a liberalidade excessiva.” (LIVRO BRANCO DA PREVIDÊNCIA SOCIAL, p. 17).

Vale lembrar que EC $\mathrm{n}^{\circ}$. 20/98 foi promulgada no encerramento do ano legislativo, sendo que sua votação foi acelerada nos últimos meses da legislatura sob o alarde da crise econômica em meados de outubro do mesmo ano, o que fez com que o debate acerca das questões envolvidas na reforma fosse feito tão somente "pelo enfoque econômico, atuarial e dos resultados financeiros esperados com a aprovação do texto" (CASTRO, LAZZARI, 2015, p. 389).

Também foi estabelecida a livre concorrência entre o RGPS e as seguradoras da iniciativa privada para a cobertura do risco de acidentes de trabalho - o que se daria mediante regulamentação por lei ordinária - confirmando mais uma vez a tendência dessa reforma aos ideais neoliberais.

E, diferentemente das justificativas constantemente defendidas pelo então Presidente da República, a "Emenda trouxe, basicamente, reduções de despesas no que tange aos benefícios do regime geral, gerido pelo INSS, não tendo sido tomada qualquer medida para o aumento da arrecadação" (CASTRO e LAZZARI, 2015, p. 80).

Menos de um ano depois, em 26 de novembro de 1999, a Lei ${ }^{\circ} 9.876$ instituiu o fator previdenciário, além de um aumento considerável no Período Básico de Cálculo (PBC). Referido fator trouxe indiscutível prejuízo aos segurados, pois nada mais é que um fator 
redutor do valor da aposentadoria por tempo de contribuição, que visa a diminuir as despesas com a concessão desse benefício aos segurados com idades abaixo da considerada "ideal" para a aposentação.

E os reiterados fundamentos do déficit da Previdência Social e do equilíbrio financeiro e atuarial foram novamente aventados:

O pressuposto lógico-jurídico da Lei n. 9.876/99 é alcançar o equilíbrio do Plano de Benefícios do RGPS. Seu escopo inicial é, a médio prazo, eliminar o déficit da Previdência Social; fundamentalmente, estabelecer correlação sinalagmática entre a contribuição (expressa por um salário-de-benefício mais largo) e o benefício, levando em consideração a esperança média de vida aferida estatisticamente quando da aposentação [...]

A questão é tormentosa: pecuniariamente, os segurados só terão o benefício da legislação anterior (por comparação), se realmente se aposentarem tardiamente. Todavia, não seria esta a dúvida remanescente, e sim se a nova lei contraria ou não o texto constitucional, ou seja, se institui ou não um limite mínimo de idade.

Verdadeiramente isso não aconteceu. O legislador trabalhou na fronteira de sua competência constitucional. (MARTINEZ, 2000, p. 01).

Após, foram instituídas novas mudanças significativas nos benefícios do RGPS através das Medidas Provisórias nº. 664/2014 (convertida na Lei nº 13.135/15, publicada em 17/06/ 2015) e no 676 (convertida na Lei 13.183/15).

A primeira trouxe consideráveis alterações à pensão por morte, especialmente no que diz respeito à duração do benefício. Anteriormente, a pensão por morte era vitalícia independentemente da idade do beneficiário, contudo, após referido diploma legal, passou à duração máxima variável, conforme a idade e o tipo do beneficiário. Atualmente, o benefício somente será vitalício se o beneficiário contar, na data do óbito, com 44 anos de idade ou mais. Também instituiu a exigência do cumprimento de 18 contribuições do segurado, o que não corresponde à carência propriamente dita, contudo, não havendo essas contribuições, a pensão será concedida apenas por 4 meses, a contar da data do óbito. Esse prazo de duração de 4 meses também se aplica para os casos em que o casamento ou a união estável tiverem perdurado por 2 anos.

Já a Lei 13.183/15, estabeleceu a chamada Regra 85/95 Progressiva, cujo cálculo deve levar em consideração o número de pontos alcançados somando a idade e o tempo de contribuição do segurado, de forma que a mulher que somar 85 pontos e o homem que somar 95 pontos, atualmente, aposentam-se sem a incidência do fator previdenciário. Entretanto, a progressividade ajusta os pontos necessários para obter a aposentadoria de acordo com a expectativa de sobrevida dos brasileiros, sem que tenha ocorrido a esperada extinção do fator previdenciário. A partir de 31 de dezembro 2018, referida soma de pontos será majorada em 1 
ponto a cada dois anos, de forma que a soma deverá corresponder a 90 pontos para mulheres e 100 pontos para homens.

Nos dias de hoje, uma nova "Reforma da Previdência" faz parte da agenda de reformas apresentada pelo atual Presidente da República, Michel Temer, e, foi proposta através da PEC 287/16, a qual está em tramitação no Congresso Nacional. A proposta já foi modificada inúmeras vezes e traz regras mais severas para a concessão e cálculo de benefícios previdenciários.

Salienta-se, contudo, que a votação da PEC, que estava prevista para o dia 20 de fevereiro de 2018, foi suspensa devido à intervenção federal na cidade do Rio de Janeiro 5 , cujo decreto foi assinado pelo Presidente da República Michel Temer em 16 de fevereiro de 2018 e deve durar até 31 de dezembro do mesmo ano.

Há mais de quinze anos o sociólogo e cientista político argentino Atilio Borón realizou reflexão que se mostra extremamente atual:

A questão essencial para avaliar as "reformas orientadas para o mercado" um eufemismo para a reestruturação neoliberal do capitalismo - deve ser: estas reformas criam uma sociedade boa ou uma sociedade melhor do que antes? Essas reformas são favoráveis à realização de uma sociedade mais justa, humana, democrática, próspera, libertadora e ecologicamente sustentável? A observação mais superficial da realidade latino-americana é suficiente para provar que não estamos nos movendo nessa direção. Não há nada que valha um orçamento fiscal equilibrado, uma inflação zero ou um excedente da balança comercial se nossas sociedades se derrubarem, se a miséria proliferar nas cidades e campos, se todos os dias houverem mais crianças que crescem nas ruas, se os desempregados são uma legião em constante crescimento, se o emprego é precário e os salários não são suficientes, se o crime nos oprimir e se a sociedade se separar em um polo que está em desacordo com a sua opulência e outro que não pode mais esconder sua indigência. Era hora de silenciar a economia e ouvir novamente a teoria política e a filosofia moral. (BORON, 2000, p. 110, tradução da autora)

Assim, em que pese a erradicação da pobreza e da marginalização e a redução das desigualdades sociais e regionais sejam objetivos fundamentais da República Federativa do Brasil - nos termos do art. $3^{\circ}$, III da CF/88 -, bem como a previdência social tenha sido elencada como direito social pelo art. $6^{\circ}$ da CF/88, o Brasil está, desde 1988 até hoje, tomando um caminho distante disso.

Até o momento, nenhum governo teve a coragem de cogitar uma proposta como essa: institucionalizar, promovendo mudança na Constituição, que o pagamento do serviço da dívida preceda a preocupação de realizar os atuais

\footnotetext{
${ }^{5}$ Nos termos do artigo $60, \S 1^{\circ}$ da $\mathrm{CF} / 88$, a Constituição não poderá ser emendada na vigência de intervenção federal. Dessa forma, também levando-se em conta a eleição presidencial que ocorrerá em outubro de 2018, a discussão acerca do futuro da Previdência Social no Brasil será oportunamente prorrogada para os próximos anos.
} 
níveis de gastos sociais, quanto mais de ampliá-los. (MARQUES in MARQUES, FERREIRA, 2010, p. 18)

O RGPS se pauta tanto na reposição de renda em caso de perda de capacidade laborativa quanto na redução da pobreza por meio da distribuição de recursos de grupos mais afluentes para os menos.

Em se tratando de distribuição de renda e redução de desigualdades sociais, conforme estudado no primeiro ponto, as políticas públicas de Previdência Social têm papel extremamente importante, especialmente levando-se em conta o efeito distributivo dos benefícios previdenciários, isto é, o impacto que o gasto previdenciário gera sobre a desigualdade de renda.

No ano 2009 - utilizado como parâmetro aqui - o Brasil se manteve como um dos dez países - especificamente na oitava posição - com maior desigualdade social do mundo segundo o relatório do PNUD (Programa das Nações Unidas para o Desenvolvimento) sobre o IDH (Índice de Desenvolvimento Humano) em 177 países, sendo que 46,9\% da renda nacional pertence aos $10 \%$ mais ricos, enquanto os $10 \%$ mais pobres ficam com apenas $0,7 \%$ da renda (ARCARY, 2011, p. 43).

Não obstante a qualidade de vida no Brasil seja consideravelmente superior à que tínhamos há vinte anos, o problema reside na "grande distância entre o topo e a base da sociedade, com enorme número de excluídos", de forma que "ainda há muito a fazer, tanto em quantidade como qualidade." (GRAÇA, 2013, p. 242).

Ainda, de acordo com estudos realizados pelo economista francês Thomas Piketty citado anteriormente, referentes à Pesquisa Desigualdade Mundial 2018, quase 30\% da renda do Brasil está nas mãos de apenas $1 \%$ dos habitantes do país, a maior concentração do tipo no mundo (BORGES, 2017).

Jorge Paulo Lemann (AB Inbev), Joseph Safra (Banco Safra), Marcel Hermmann Telles (AB Inbev), Carlos Alberto Sicupira (AB Inbev), Eduardo Saverin (Facebook) e Ermirio Pereira de Moraes (Grupo Votorantim) são as seis pessoas mais ricas do Brasil. Eles concentram, juntos, a mesma riqueza que os 100 milhões mais pobres do país, ou seja, a metade da população brasileira (207,7 milhões). Estes seis bilionários, se gastassem um milhão de reais por dia, juntos, levariam 36 anos para esgotar o equivalente ao seu patrimônio. Foi o que revelou um estudo sobre desigualdade social realizado pela Oxfam.

O levantamento também revelou que os $5 \%$ mais ricos detêm a mesma fatia de renda que os demais $95 \%$ da população. Além disso, mostra que os super ricos $(0,1 \%$ da população brasileira hoje) ganham em um mês o mesmo que uma pessoa que recebe um salário mínimo (937 reais) - cerca de $23 \%$ da população brasileira - ganharia trabalhando por 19 anos seguidos. Os dados também apontaram para a desigualdade de gênero e raça: mantida a tendência dos últimos 20 anos, mulheres ganharão o mesmo salário que 
homens em 2047, enquanto negros terão equiparação de renda com brancos somente em 2089. (ROSSI, 2017)

Essa é a realidade da população brasileira, de várias localidades e grupos sociais, tendo em vista que o Brasil é um país de dimensões continentais e marcado por extrema desigualdade social.

Um estudo publicado pelo Ministério da Fazenda em 2016 demonstra que os benefícios pagos pela Previdência Social produzem consideráveis impactos sobre o nível de pobreza da população brasileira:

Ainda de acordo com a PNAD/IBGE, pode-se observar que os benefícios
pagos pela Previdência Social produzem impactos significativos sobre o
nível de pobreza da população brasileira. Assumindo como condição de
pobreza a percepção de rendimento domiciliar per capita inferior a meio
salário mínimo, estima-se em 52,95 milhões a quantidade de pessoas em
condiçãa de pobreza em 2015 (considerando rendas de todas as fontes). Caso
fossem desconsiderados os rendimentos advindos do recebimento de
benefícios previdenciários, a quantidade de pobres seria de 81,18
milhões, o que significa dizer que o pagamento de benefícios pela
Previdência Social retira da condição de pobreza cerca de 28,23
milhões de indivíduos - redução de 14,1 pontos percentuais na taxa de
pobreza. (INFORME DA PREVIDÊNCIA SOCIAL, 2016, p. 07)

Além disso, é possível afirmar que a Previdência Social depende do crescimento econômico e do mercado de trabalho, uma vez que a queda do valor médio de renda dos segurados igual e consequentemente reflete um cenário de redução do valor dos benefícios previdenciários, que são calculados conforme salários de contribuição.

A análise dos Anuários Estatísticos da Previdência Social realizada por Fabio Luiz dos Passos demonstra o empobrecimento dos beneficiários da Previdência Social, a começar pelo teto de renda dos benefícios previdenciários, o qual vem sendo reduzido gradualmente desde 1994, com a instituição do plano real, quando correspondia a 8,3 salários-mínimos, chegando a corresponder menos de 6,5 salários-mínimos a partir de 2012 e a menos de 6 salários mínimos em 2015 e 2016; todavia, esse limite máximo não representa o valor médio dos benefícios previdenciários, que:

Conforme demonstra o Informe de Previdência Social, o valor médio dos benefícios previdenciários (tendo por base o mês de dezembro de cada ano) equivalia a aproximadamente seis salários mínimos em 1995, chegando a dois salários mínimos em 2008 e correspondia a aproximadamente 1,3 salários mínimos em dezembro de 2014.

Ao longo dos 22 anos de existência do plano real, o limite máximo de renda disponibilizado a título de benefício previdenciário foi gradativamente reduzido, correspondendo (em relação ao número de salários mínimos), em 2016, a 71\% do que correspondia em número de salários mínimos em 1994.

Já o valor médio de renda dos benefícios previdenciários reduziu $79 \%$ no período de 1995 a 2014. Ou seja, o valor médio dos benefícios 
previdenciários pagos em dezembro de 2014 equivale a apenas $21 \%$ dos valor médio dos benefícios previdenciários pagos em dezembro de 1995, quando comparados ao salário mínimo. (PASSOS in BERWANGER; SERAU JUNIOR; FOLMANN, 2016, p. 51-51)

E, ainda, com relação aos idosos, Amélia Camarano observa que o papel desempenhado pela renda decorrente de benefícios previdenciários é ainda maior:

as aposentadorias desempenham um papel muito importante na renda dos idosos e essa importância cresce com a idade. Pode-se concluir que o grau de dependência dos indivíduos idosos é, em boa parte, determinado pela provisão de rendas por parte do Estado. Como uma parcela importante da renda familiar depende da renda do idoso, sugere-se que quando se reduzem ou se aumentam benefícios previdenciários, o Estado não está simplesmente atingindo indivíduos, mas uma fração razoável dos rendimentos de famílias inteiras. Isso é importante de ser notado porque, como conseqüência, o perfil do sistema previdenciário construído hoje influirá na distribuição futura da renda das famílias. (CAMARANO, 2002, p.23)

Impende salientar colocação de Esteves e Barbosa no sentido de que tanto o sistema público de previdência quanto o privado são sensíveis à alteração demográfica, de forma que a diminuição da taxa de emprego que normalmente ocorre em períodos de crises econômicas “abala, substancialmente, qualquer sistema previdenciário, levando idosos, já aposentados, de volta ao trabalho, mas em condições ainda mais precarizadas do que quando saíram" (ESTEVES; BARBOSA in BERWANGER; SERAU JUNIOR; FOLMANN, 2016, p. 128).

Nessa perspectiva, é importante ressaltar novamente que o artigo $3^{\circ}$ da $\mathrm{CF} / 88$ elenca como objetivos fundamentais da República Federativa do Brasil: construir uma sociedade livre, justa e solidária, garantir o desenvolvimento nacional, erradicar a pobreza e a marginalização e reduzir as desigualdades sociais e regionais, e, promover o bem de todos, sem preconceitos de origem, raça, sexo, cor, idade e quaisquer outras formas de discriminação.

$\mathrm{O}$ art. 170 da $\mathrm{CF} / 88$, por sua vez, determina que a ordem econômica, fundada na valorização do trabalho humano e na livre iniciativa, tem por fim assegurar a todos existência digna, conforme os ditames da justiça social, observado o princípio da redução das desigualdades regionais e sociais.

Assim, o conceito de justiça social na Ordem Constitucional Brasileira deveria orientar a ordem social, sendo que as políticas públicas relativas ao RGPS se caracterizariam como medidas de justiça distributiva.

\section{CONSIDERAÇÕES FINAIS:}

O presente trabalho teve como objetivo apresentar uma reflexão acerca da importância do papel das políticas públicas de Previdência Social na redução da desigualdade 
e na devida redistribuição de renda, levando-se em conta o efeito distributivo dos benefícios previdenciários, isto é, o impacto que o gasto previdenciário gera sobre a desigualdade de renda. Confirmamos, por sua vez, a hipótese levantada na introdução desta pesquisa.

Conforme estudado na primeira parte deste trabalho, o tão afamado crescimento econômico não augura um futuro melhor para a maioria de nós, pelo contrário, aprofunda a pobreza e aumenta cada dia mais a desigualdade social.

O processo de mundialização do capitalismo se deu simultaneamente ao advento do neoliberalismo e afetou diretamente as políticas públicas de previdência social, as quais estão atreladas a um contexto histórico e social.

Após a análise da influência neoliberal e suas consequências para os países latinoamericanos, não restam dúvidas no sentido de que esse modelo gerou um quadro maior de desigualdades e injustiças sociais, e pior: vêm sendo hegemônico e fundamento constante para reformas referentes ao RGPS no Brasil - sempre realizadas sob a ótica meramente fiscal.

Demais, foi demonstrado que os benefícios pagos pela Previdência Social produzem consideráveis impactos sobre o nível de pobreza da população brasileira, além de que aquela depende do crescimento econômico e do mercado de trabalho, uma vez que a queda do valor médio de renda dos segurados igual e consequentemente reflete um cenário de redução do valor dos benefícios previdenciários, que são calculados conforme salários de contribuição.

Em que pese tudo isso, o valor médio dos benefícios previdenciários vem sendo reduzido gradativamente, assim como o limite máximo de renda disponibilizado a título de benefício previdenciário, de acordo com o demonstrado.

Não se pode olvidar, ainda, do aumento constante da expectativa de vida do brasileiro e do papel desempenhado pela renda decorrente de benefícios previdenciários percebidos por idosos, a qual possui influência direta na distribuição futura de renda das famílias.

Assim, após o estudo realizado sob o enfoque da justiça social, foi possível concluir que o seu conceito na Ordem Constitucional Brasileira deveria orientar a ordem social, sendo que as políticas públicas relativas ao RGPS se caracterizariam como medidas de justiça distributiva, e, servindo como importante reflexão para discussão no XXVII Congresso Nacional do CONPEDI.

\section{REFERENCIAIS BIBLIOGRÁFICAS:}

ARCARY, Valério. Um reformismo quase sem reformas - Uma crítica marxista do governo Lula em defesa da Revolução Brasileira. São Paulo: Editora Instituto José Luis e Rosa Sundermann, 2011. 
BAUMAN, Zygmunt. A riqueza de poucos beneficia todos nós? Tradução Renato Aguiar. 1.ed. Rio de Janeiro: Zahar, 2015.

BELLO, Enzo. A cidadania no constitucionalismo latino-americano. Caxias do Sul, RS: Educs, 2012.

BERWANGER, Jane Lucia Wilhelm; SERAU JUNIOR, Marco Aurélio; FOLMANN, Melissa (coordenadores). Previdência Social? Porto Alegre: Magister, 2016.

BORGES, Rodolfo. Brasil tem maior concentração de renda do mundo entre o $1 \%$ mais rico. Jornal El País. Madri, 14 de dezembro de 2017. Disponível em < https://brasil.elpais.com/brasil/2017/12/13/internacional/1513193348_895757.html> Acesso em 05 de abril de 2018.

BORON, Atilio A.. 1. El manifiesto comunista hoy: permanencias, obsolescencias, ausencias. En publicacion: Tras el búho de Minerva. Mercado contra democracia en el capitalismo de fin de siglo Atilio A. Boron CLACSO, Consejo Latinoamericano de Ciencias Sociales, Ciudad Autónoma de Buenos Aires, Argentina. 2000. ISBN: 950-557-388-x . Disponível em: < http://bibliotecavirtual.clacso.org.ar/ar/libros/buho/cap1.rtf> Acesso em 08 de agosto de 2017.

BOSCHETI, Ivanete (et al.). Capitalismo em crise, política social e direitos. São Paulo: Cortez, 2010.

BRAUNER, Maria Claudia Crespo; LOBATO, Anderson Orestes Cavalcante (org.). Direito e Justiça Social: a construção jurídica dos direitos de cidadania. Rio Grande: Editora da Furg, 2015.

CASTRO, Carlos Alberto Pereira de; LAZZARI, João Batista. Manual de direito previdenciário. Rio de Janeiro: Forense, 2015.

CAMARANO, Ana Amélia. Envelhecimento da população brasileira: uma contribuição demográfica. Brasília: Instituto de Política Econômica Aplicada, 2002.

CHESNAIS, François. A mundialização do capital. Tradução Silvana Finzi Foá. São Paulo: Xamã, 1996.

FÉLIX, Jorge. Viver muito: outras ideias sobre envelhecer bem no séc. XXI (e como isso afeta a economia e o seu futuro). São Paulo: Leya, 2010.

FERRARO, Alceu Ravenello. Neoliberalismo e políticas sociais: a naturalização da exclusão. Disponível em http://www3.est.edu.br/publicacoes/estudos_teologicos/vol4501_2005/et20051f_aferraro.pdf> Acesso em 02 de abril de 2018.

FRIEDMAN, Milton. Capitalismo e Liberdade. 3. ed. São Paulo: Nova Cultural, 1988.

GRAÇA, Milton Coelho da (Org.). Roberto Freire - a esquerda sem dogma. Brasília: Fundação Astrojildo Pereira (FAP), 2013.

HARVEY, David. O Neoliberalismo: História e Implicações. São Paulo, Edições Loyola, 2008. (Título Original: A brief history of neoliberalism, 2005)

KATZ, Claudio. Neoliberalismo, neodesenvolvimentismo, socialismo. 1.ed. São Paulo: Expressão Popular, 2016.

LIVRO BRANCO DA PREVIDÊNCIA SOCIAL. Ministério da Previdência e Assistência Social, Brasília/DF: $1997 . \quad$ Disponível em: 
http://www.biblioteca.presidencia.gov.br/presidencia/ex-presidentes/fernando-henriquecardoso/publicacoes/por-que-reformar-a-previdencia-livro-branco-da-previdencia-social> Acesso em 12 de junho de 2017.

MARQUES, Rosa Maria; FERREIRA, Mariana Ribeiro Jansen (org.). O Brasil sob nova ordem: a economia brasileira contemporânea: uma análise dos governos Collor a Lula. São Paulo: Saraiva, 2010.

MARTINEZ, Wladimir Noaves. Nova forma de cálculo de benefício previdenciário. Revista Jurídica Virtual. Brasília, vol. 1, n. 10, março 2000. Disponível em: < https://revistajuridica.presidencia.gov.br/index.php/saj/article/view/1045/1029> Acesso em 17 de junho de 2017.

MARTINS, Carlos Eduardo. Globalização, dependência e neoliberalismo na América Latina. São Paulo: Boitempo, 2011.

OSTRY, Jonathan D.; LOUNGANI, Prakash; FUCERI, Davide. "Neoliberalism: oversold?". Finance \& Development, Junho de 2016. pp. 38-41. Disponível em < https://www.imf.org/external/pubs/ft/fandd/2016/06/pdf/ostry.pdf> Acesso em 28 de novembro de 2016.

PEREIRA, Potyara. A Política Social no contexto da Seguridade Social e do Welfare State: a particularidade da assistência social. Serviço Social e Sociedade. $\mathrm{n}^{\circ}$. 55. Ano XVIII - Nov. 1997. p. 60-76.

PIKETTY, Thomas. A economia da desigualdade. Tradução André Telles.1.ed. Rio de Janeiro: Intrínseca, 2015.

ROSSI, Marina. Seis brasileiros concentram a mesma riqueza que a metade da população mais pobre. Jornal El País. Madri, 25 de setembro de 2017. Disponível em < https://brasil.elpais.com/brasil/2017/09/22/politica/1506096531_079176.html> Acesso em 05 de abril de 2018.

SANTOS, Boaventura de Sousa (org.). A Globalização e as ciências sociais. São Paulo: Cortez, 2002.

The Prize in Economics 1974 - Press Release. Nobelprize.org. Nobel Media AB 2014. Web. Disponível em: http://www.nobelprize.org/nobel_prizes/economicsciences/laureates/1974/press.html Acesso em 03 de abril de 2018.

The Sveriges Riksbank Prize in Economic Sciences in Memory of Alfred Nobel 1976". Nobelprize.org. Nobel Media AB 2014. Dispojnível em: http://www.nobelprize.org/nobel_prizes/economic-sciences/laureates/1976/ Acesso em 03 de abril de 2018. 